\title{
Gastro-oesophageal reflux in mechanically ventilated patients: effects of an oesophageal balloon
}

\author{
M. Orozco-Levi*, M. Félez*, E. Martínez-Miralles\#, J.F. Solsona", M.L. Blanco*, J.M. Broquetas*, \\ A. Torres $^{+}$
}

Gastro-oesophageal reflux in mechanically ventilated patients: effects of an oesophageal balloon. M. Orozco-Levi, M. Félez, E. Martínez-Miralles, J.F. Solsona, M.L. Blanco, J.M. Broquetas, A. Torres. (C) ERS Journals Ltd 2003.

ABSTRACT: Gastro-oesophageal reflux (GOR) and bronchoaspiration of gastric content are risk factors linked with ventilator-associated pneumonia. This study was aimed at evaluating the effect of a nasogastric tube (NGT) incorporating a low-pressure oesophageal balloon on GOR and bronchoaspiration in patients receiving mechanical ventilation.

Fourteen patients were studied in a semi-recumbent position for 2 consecutive days. Inflation or deflation of the oesophageal balloon was randomised. Samples of blood, gastric content, and oropharyngeal and bronchial secretions were taken every 2 h over a period of $8 \mathrm{~h}$. A radioactively labelled nutritional solution was continuously administered through the NGT. The magnitude of both the GOR and bronchoaspiration was measured by radioactivity counting of oropharyngeal and bronchial secretion samples, respectively.

Inflation of the oesophageal balloon resulted in a significant decrease of both GOR and bronchoaspiration of gastric content. This protective effect was statistically significant from $4 \mathrm{~h}$ following inflation throughout the duration of the study.

This study demonstrates that an inflated oesophageal balloon delays and decreases gastro-oesophageal and bronchial aspiration of gastric content in patients carrying a nasogastric tube and receiving enteral nutrition during mechanical ventilation. Although the method was found to be safe when applied for $8 \mathrm{~h}$, longer times should be considered with caution.

Eur Respir J 2003; 22: 348-353.
*Servei de Pneumologia, Hospital del Mar, and Unitat de Recerca Respiratòria i Ambiental, IMIM, and CEXS-Universitat Pompeu Fabra,

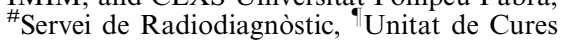
Intensives, Hospital del Mar, Universitat Autònoma de Barcelona, ${ }^{+}$Servei de Pneumologia i Allergia Respiratòria, Institut Clínic de Pneumologia i Cirurgia Toràcica, IDIBAPS, Hospital Clínic de Barcelona, Spain.

Correspondence: M. Orozco-Levi, Unitat de Recerca Respiratòria i Ambiental, IMIM, Carrer Dr. Aiguader 80, Barcelona, E-08003, Spain.

Fax: 34932213237

E-mail: morozco@imim.es.

Keywords: Gastro-oesophageal reflux oesophageal balloon

ventilator-associated pneumonia

Received: June 62002

Accepted after revision: March 82003

Supported in part by grants FIS 96/1078 and SEPAR (FEPAR-Infecciones 95).
Nosocomial pneumonia has an incidence of one patient per 100 hospital admissions and has a high mortality rate $[1,2]$. Patients requiring mechanical ventilation possess a higher risk of developing nosocomial pneumonia than nonventilated patients. Ventilator-associated pneumonia (VAP) has a cumulative incidence ranging from $18-60 \%$ and has been found in $>70 \%$ of patients who died from acute lung injury [3-5]. One of the most commonly recognised risk factors for VAP is the bacterial colonisation of the gastric content with subsequent gastrooesophageal reflux (GOR) and aspiration into the airways [6, 7]. The GOR has been found to be enhanced in mechanically ventilated patients maintained in the supine body position and in patients carrying a nasogastric tube (NGT), because these factors appear to increase the permeability of the lower oesophageal sphincter [8-10].

Several groups find it reasonable and clinically relevant to further investigate new potential preventive measures, which are applicable to conventional clinical settings, have little or no impact on selecting resistant microorganisms, and are economically viable. In this regard, several mechanical preventive measures have been evaluated, including intermittent [11] or continuous [12] subglotic aspiration, avoidance of NGT [10], small-bore NGT [13, 14], and semi-recumbent body positioning [9]. In 1992, the supine body position and the duration of the time spent in the supine position were associated with an increased risk of aspirating the gastric content into the airways [9]. Consequently, the semi-recumbent body position was proposed as a potential prophylactic manoeuvre to reduce GOR and prevent VAP [9]. Recently, the current authors showed that maintaining mechanically ventilated patients in a semi-recumbent position reduces the incidence of VAP from 34 to $8 \%$ [15]. In a subsequent study, however, the semi-recumbent position was not found to fully protect the patient from GOR or oropharyngeal colonisation of gastric origin [16]. Most of these studies were carried out without enteral nutrition and thus under conditions of low gastric content which may have resulted in an underestimation of GOR [17].

The authors hypothesise that other mechanical measures aimed at reducing GOR in mechanically ventilated patients may exist. A significant reduction of GOR could decrease the incidence of VAP in these patients $[12,15]$. The present study evaluated the effect of a NGT incorporating an inflated oesophageal balloon on the magnitude and dynamics of GOR over an 8-h period in mechanically ventilated patients receiving continuous enteral nutrition and maintained in a semi-recumbent body position.

\section{Methods}

\section{Study population}

Fourteen patients (nine male; aged $66 \pm 3$ yrs) receiving mechanical ventilation through an orotracheal tube and 
tolerating enteral nutrition were selected for the study. The study was approved by the Research Committee for Human Investigation at Hospital del Mar (Barcelona, Spain). Informed written consent was obtained from the patients' next of kin. General characteristics of the study population are summarised in table 1. Exclusion criteria included previous abdominal surgery, previously documented GOR or paralytic ileum. None of the patients were sedated or paralysed during the study, since these states could alter gastric and intestinal motility. All the patients received intravenous ranitidine as a prophylactic measure against digestive bleeding. Eleven patients were being treated with antibiotics. The pressure of the orotracheal and oesophageal balloons was verified every $2 \mathrm{~h}$.

\section{Study protocol}

A 16 French diameter NGT incorporating an oesophageal balloon was used (156-16, Mallinckrodt, MO, USA) (fig. 1). This NGT was inserted and fixed in each patient at least $24 \mathrm{~h}$ prior to the start of the study. The NGT contained a special aspiration line that allowed the aspiration of secretions accumulating above the oesophageal balloon. The balloon was maintained deflated until the beginning of the corresponding study period. Prior to the start of the study, all patients had shown tolerance to enteral liquid nutrition for $\geqslant 2$ days through the NGT at $\geqslant 63 \mathrm{~mL} \cdot \mathrm{h}^{-1}$. The nutrition was not stopped before or during the study periods. On the contrary, conventional perfusion was replaced by a new flask containing the radioactively labelled solution $(10 \mathrm{mCi}$ of sulphur colloid- ${ }^{99 \mathrm{~m}} \mathrm{Tc}$ ) and the perfusion was continued at a rate of $63 \mathrm{~mL} \cdot \mathrm{h}^{-1}$. This study design allowed GOR to be evaluated in conditions of continuous enteral nutrition emulating a conventional management in mechanically ventilated patients. All patients were studied on two occasions (or periods), $24 \mathrm{~h}$ apart and defined according to the condition of the oesophageal balloon (inflated or deflated). The beginning of each two study periods was defined by the beginning of the perfusion of the labelled solution. On one occasion, the balloon was maintained inflated during the whole $8 \mathrm{~h}$ period. The balloon was inflated from the beginning of the proper period and was maintained at a constant inflation pressure of $30 \mathrm{cmH}_{2} \mathrm{O}$. When the balloon remained inflated at this pressure, its length was $14 \mathrm{~cm}$ whereas its diameter was $3 \mathrm{~cm}$. Positioning of the balloon was defined to be correct when it was localised in the middle third of the oesophageal length.

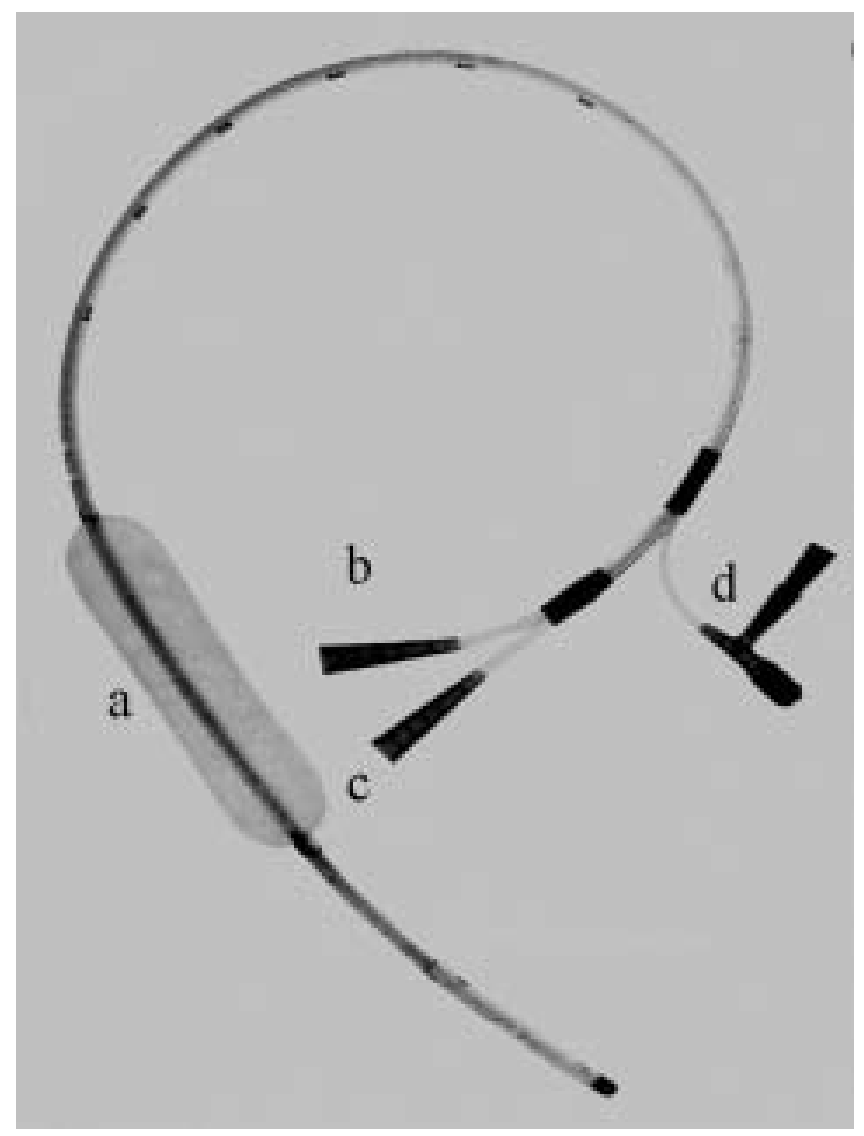

Fig. 1.- Photograph showing the $(16 \mathrm{~F})$ nasogastric tube incorporating a: oesophageal balloon; b: oesophageal line allowing the aspiration of secretions and/or gastro-oesophageal reflux accumulating above the balloon; c: gastric line; and d: air line for inflation and deflation of the balloon. For methodological specifications, see text.

This localisation of the balloon was selected on the empirical basis that it could affect, in a lesser manner, the dynamics of the gastro-oesophageal sphincter or pharyngo-laryngeal region than a more proximal or distal positioning. Correct positioning was monitored by chest radiograph according to radioopaque imaging of the tube. On the other occasion, the balloon was maintained deflated during the whole $8 \mathrm{~h}$ period.

Table 1.-General characteristics of the study population

\begin{tabular}{|c|c|c|c|c|c|c|c|}
\hline Patient no. & Diagnoses & Age yrs & Sex & MV days & $F \mathrm{I}, \mathrm{O}_{2} \mathrm{mmHg}$ & $\mathrm{PEEP} \mathrm{cmH}_{2} \mathrm{O}$ & $\mathrm{Pa}, \mathrm{O}_{2} \mathrm{mmHg}$ \\
\hline 1 & Ischaemic encephalopathy & 83 & $\mathrm{~F}$ & 9 & 0.4 & 6 & 107 \\
\hline 2 & Intracranial infarction & 70 & M & 11 & 0.4 & 5 & 113 \\
\hline 3 & Community-acquired pneumonia & 56 & $\mathrm{M}$ & 7 & 0.3 & 0 & 126 \\
\hline 4 & Community-acquired pneumonia & 66 & $\mathrm{~F}$ & 4 & 0.4 & 0 & 132 \\
\hline 5 & Community-acquired pneumonia & 60 & $\mathrm{~F}$ & 7 & 0.5 & 0 & 116 \\
\hline 6 & Nosocomial-acquired pneumonia & 48 & M & 5 & 0.5 & 5 & 165 \\
\hline 7 & COPD-ARF & 72 & $\mathrm{~F}$ & 7 & 0.4 & 16 & 150 \\
\hline 8 & COPD-ARF & 75 & $\mathrm{~F}$ & 4 & 0.4 & 0 & 68 \\
\hline 9 & COPD-ARF & 64 & M & 9 & 0.4 & 5 & 105 \\
\hline 10 & COPD-ARF & 65 & $\mathrm{~F}$ & 8 & 0.4 & 0 & 89 \\
\hline 11 & Pulmonary fibrosis & 64 & M & 9 & 0.5 & 6 & 87 \\
\hline 12 & Ischaemic encephalopathy & 48 & M & 5 & 0.4 & 0 & 153 \\
\hline 13 & Intracranial bleeding & 69 & M & 12 & 0.4 & 0 & 124 \\
\hline 14 & COPD-ARF & 74 & M & 17 & 0.4 & 7 & 120 \\
\hline Mean \pm SD & & $65 \pm 3$ & $6 \mathrm{~F} / 8 \mathrm{M}$ & $8 \pm 1$ & $0.4 \pm 0.0$ & $4 \pm 1$ & $118 \pm 7$ \\
\hline
\end{tabular}

MV: mechanical ventilation; $F \mathrm{I}, \mathrm{O}_{2}$ : inspiratory oxygen fraction; PEEP: positive end-expiratory pressure; $P \mathrm{a}, \mathrm{O}_{2}$ : arterial oxygen tension; $\mathrm{COPD}$ : chronic obstructive pulmonary disease; ARF: acute respiratory failure; F: female; M: male. 
The sequence of the two balloon conditions was randomised. On both occasions, the patients remained in a semi-recumbent position and all were ventilated in a synchronised mandatory ventilation mode throughout the duration of the study. The samples of blood, bronchial, oropharyngeal and gastric secretions were sequentially obtained immediately prior to, and at 2-h intervals during administration of the labelled enteral nutrition. Using an ionisation chamber (Ludlum 2200, Measurements Inc, Texas, USA) the radioactivity count (RAc) was obtained and normalised to $1 \mathrm{~mL}$ in each sample. The results were corrected for decay and expressed as $\log 10$ of counts per minute (cpm). In eight patients, a fibre-endoscopic study was performed with the aim of detecting possible lesions in the oesophageal epithelium.

\section{Statistical analysis}

Data are expressed as mean \pm SEM. The slope of the regression lines was included in the analyses as a summary measure [18] in order to compare the time course of RAc in the two balloon conditions (deflated versus inflated). For the gastric Rac, analysis of the regression slope was performed by omitting time zero. The effect of the inflated or deflated balloon within an individual was compared using the paired t-test. Statistical significance was defined as a $\mathrm{p}<0.05$.

\section{Results}

General characteristics of the study population are summarised in table 1. Potential complications associated with the use of the oesophageal balloon were not observed either during the study or during the hours immediately following the study. No lesions were observed in the endoscopic studies performed in a subset of patients. The mean volume of the samples obtained was $7.5 \pm 0.4 \mathrm{~mL}$ (oropharyngeal secretions); $3.4 \pm 0.2 \mathrm{~mL}$ (bronchial secretions); $5.2 \pm 0.3 \mathrm{~mL}$ (gastric content); and $3.2 \pm 0.5 \mathrm{~mL}$ (blood).

Baseline RAc was similar for both study conditions (i.e. inflated or deflated oesophageal balloon, respectively) in oropharyngeal secretions $(3.0 \pm 0.2$ versus $2.8 \pm 0.2 \mathrm{cpm})$, bronchial secretions $(2.8 \pm 0.1$ versus $2.6 \pm 0.1 \mathrm{cpm})$, gastric content $(2.7 \pm 0.1$ versus $2.6 \pm 0.1 \mathrm{cpm})$ and blood samples $(2.4 \pm 0.1$ versus $2.4 \pm 0.1 \mathrm{cpm})$ (fig. 2).

No differences associated with the inflation state of the balloon were found in the RAc values in gastric or blood samples (fig. 2). Oropharyngeal and bronchial RAc increased during the study period (fig. 3). However, these increases were lower when the oesophageal balloon was inflated. Both the absolute values of RAc counts (fig. $3 \mathrm{a}$ and $\mathrm{b}$ ) and slope of the RAc regression lines (inflated, $0.18 \pm 0.03$ versus deflated, $0.29 \pm 0.03 ; \mathrm{p}<0.05)$ from oropharyngeal secretions were significantly decreased by the inflation of the oesophageal balloon. This difference reached statistical significance $(\mathrm{p}<0.05)$ at 4,6 and $8 \mathrm{~h}$ time points. Therefore, the increase of RAc from bronchial secretions (which reflected bronchoaspiration of gastric contents) was also significantly delayed and diminished when the oesophageal balloon was inflated (fig. $3 \mathrm{c}$ and d). The slope of the RAc regression lines in bronchial secretions was lower in the studies using the inflated oesophageal balloon $(0.1 \pm 0.1$ versus $0.2 \pm 0.1 ; \mathrm{p}<0.01)$.

\section{Discussion}

This is the first study showing that both the magnitude and rate of GOR as well as subsequent bronchoaspiration of
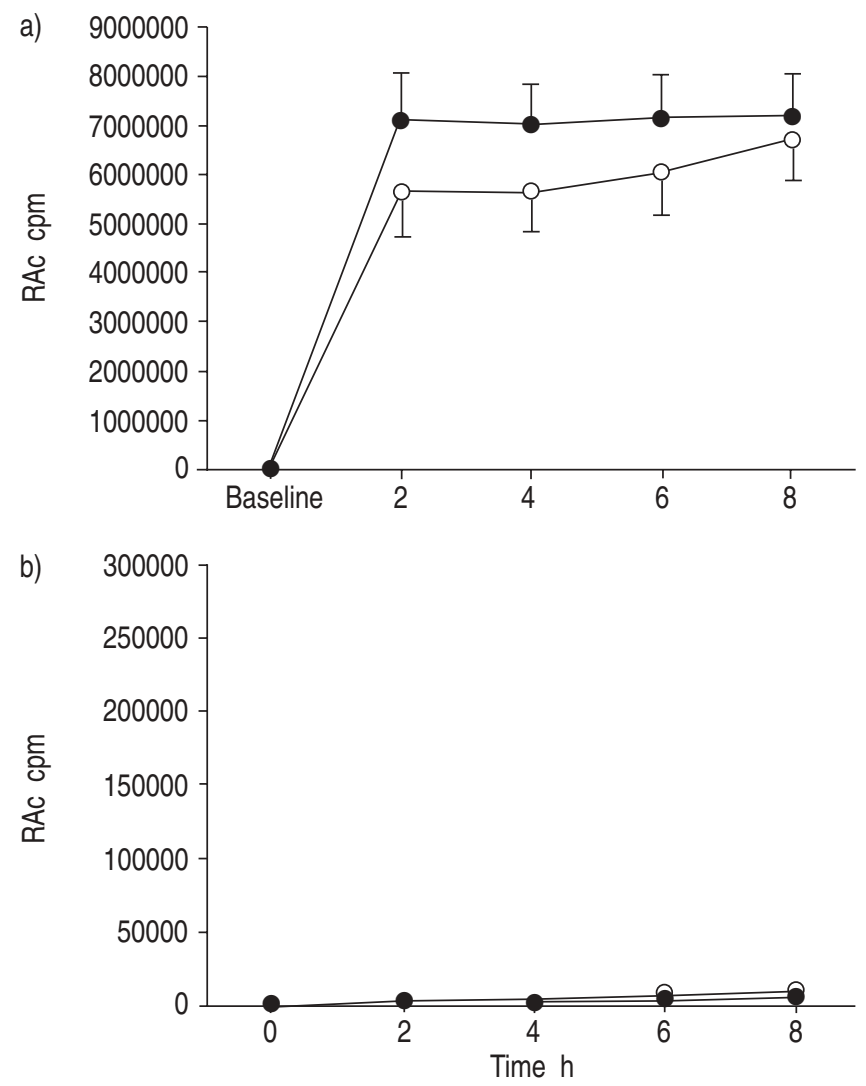

Fig. 2. - Radioactivity counting (RAc) of a) gastric, b) blood obtained immediately prior to (time 0 ) and at 2 -h intervals, following administration of continuous enteral nutrition via the nasogastric tube. The nutritional solution was radioactively labelled with $10 \mathrm{mCi}$ of sulphur colloid ${ }^{-99 \mathrm{~m}} \mathrm{Tc}$. Each patient was studied at random on two occasions, once with the oesophageal balloon deflated $(\bigcirc)$ and $24 \mathrm{~h}$ later with the balloon inflated $(\bullet)$. RAc was normalised to $1 \mathrm{~mL}$ in each sample. For technical specifications, see text.

gastric contents can be significantly decreased in patients receiving mechanical ventilation and enteral nutrition by using a NGT incorporating an inflatable oesophageal balloon. From a clinical point of view, these results suggest that a NGT with an inflated oesophageal balloon could be an additional measure to prevent nosocomial pneumonia in mechanically ventilated patients.

\section{Previous studies}

A commonly recognised risk factor for VAP is the bacterial colonisation of the gastric content and its subsequent aspiration into the airways due to GOR $[6,7]$. The virulence of the bacterial species, capacity of pulmonary defence mechanisms and size of the bacterial inoculum are also decisive factors in the development of nosocomial pneumonia. Various potential mechanisms have been implicated in the presence of GOR during mechanical ventilation: the dynamic deterioration of salivary clearance [19], the pharmacological inhibition of oesophageal motility as a result of sedatives and paralysing agents [20], nasogastric intubation [8, 10], high gastric volume [21] and a supine body position $[9,10]$. Despite knowledge of the causes which provoke this condition, no method has been able to show complete elimination of GOR from mechanically ventilated patients. Several studies have shown that some mechanical strategies are capable of decreasing the size of 

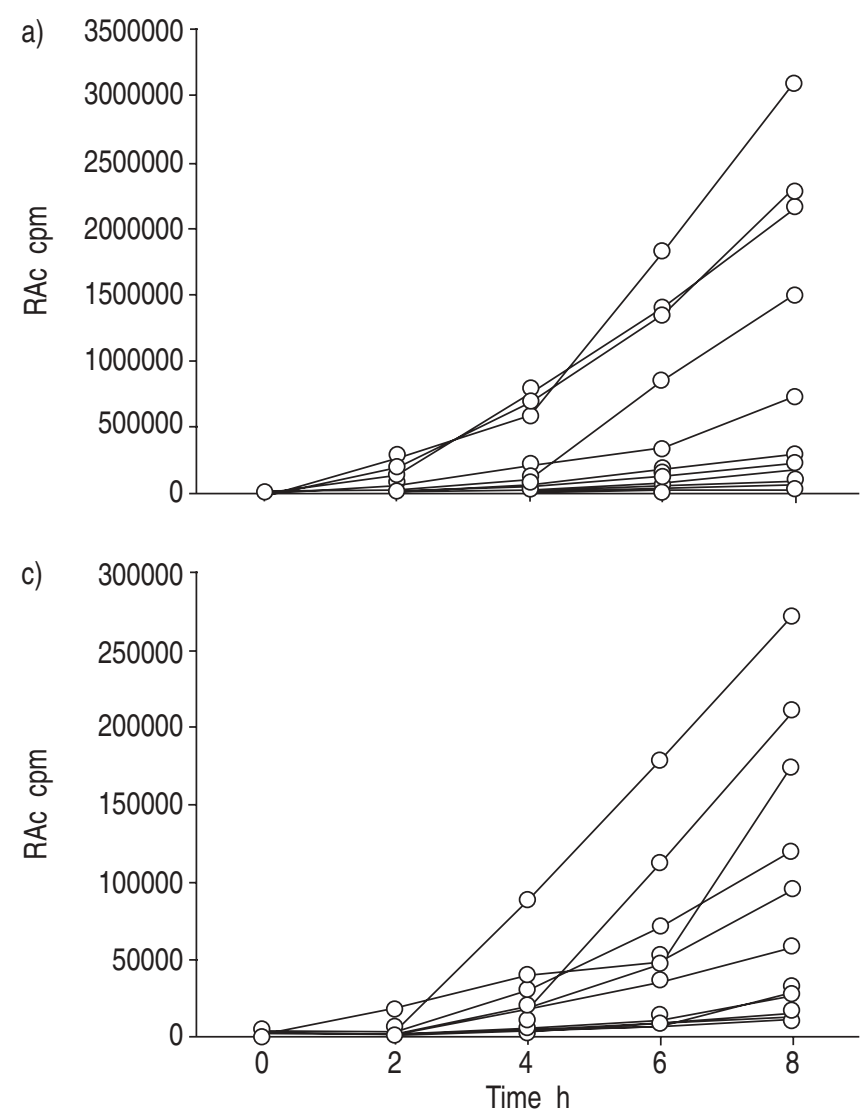

b)

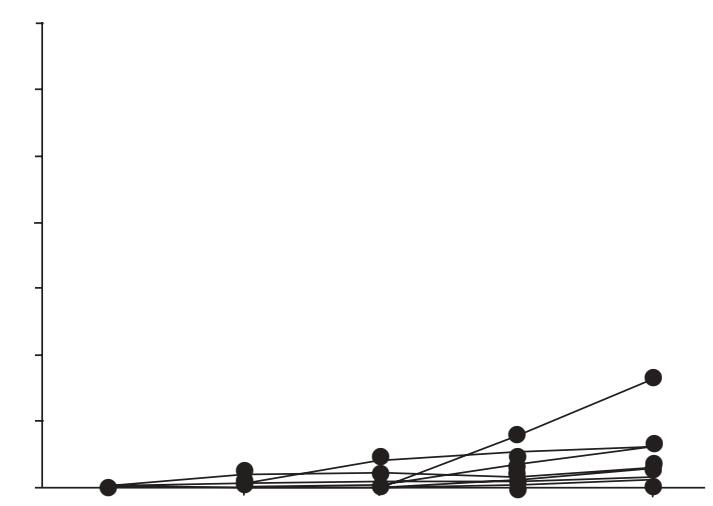

d)

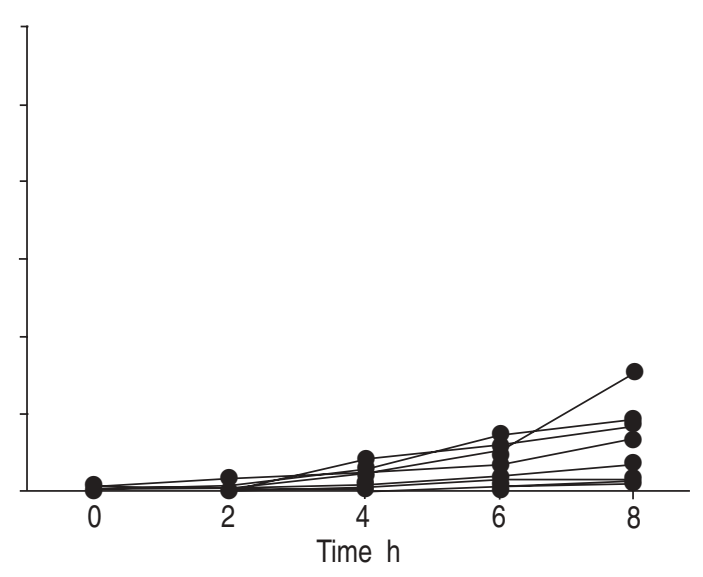

Fig. 3. - Radioactivity counting (RAc) of a) and b) oropharyngeal, and c) and d) bronchial samples, respectively, obtained immediately prior to (time 0 ) and at 2-h intervals, following administration of continuous enteral nutrition via the nasogastric tube. The nutritional solution was radioactively labelled with $10 \mathrm{mCi}$ of sulphur colloid $-{ }^{99 \mathrm{~m}} \mathrm{Tc}$. Each patient was studied at random on two occasions, a) and c) once with the oesophageal balloon deflated, and b) and d) $24 \mathrm{~h}$ later with the balloon inflated. RAc was normalised to $1 \mathrm{~mL}$ in each sample. For technical specifications, see text.

inoculum and preventing VAP. A recent study demonstrated that both supine body position and enteral nutrition are significant risk factors for VAP [14]. It is likely that these two factors are related to aspiration of gastric contents into the lower airways. In fact, it was also demonstrated that the semirecumbent body position decreases GOR and reduces the incidence of VAP from 34 to $8 \%$ [14]. VALLES et al. [12] confirmed the importance of continuous aspiration of subglotic secretions in preventing bronchial microaspirations, reducing the incidence (39.6 to 19.9 episodes $1000^{-1}$ ventilator days) and increasing the length of time before onset $(6 \pm 7$ to $12 \pm 7$ days) of VAP in patients receiving mechanical ventilation.

The current authors' group showed in two studies that the semi-recumbent body position is not capable of fully impeding GOR in patients receiving mechanical ventilation $[9,16]$. The present results are consistent with the former studies [9, 16] since GOR occurred despite the semi-recumbent positioning of the patients. However, most of the previous studies were carried out in the absence of continuous enteral nutrition and thus under conditions of low gastric contents. In the present study, a premature increase of RAc was evident in both oropharyngeal and bronchial secretions compared with previous studies. This difference can be partially explained by two factors. Firstly, an ionisation chamber was used in the present study to quantify RAc. This method is highly sensitive for quantifying RAc and may be able to detect more premature changes than those detected by using a gamma chamber which appears to be a useful method for determining the topographic distribution of ${ }^{99 \mathrm{~m}} \mathrm{Tc}$ sulphur colloid. Secondly, an additional factor could be related to enteral nutrition perfusion, which was maintained during the whole study period. This allowed for the emulation of conventional management of mechanically ventilated patients and it is possible that patients involved in the present study disclosed a higher gastric volume or lower venting effect of the NGT [21].

An alternative approach for obviating the need for an oesophageal balloon is to use a small-bore NGT. However, this technique has already been evaluated in two previous studies that showed contradictory results [13, 14]. Firstly, IBÁÑEZ et al. [13] demonstrated that a small-bore NGT results in a decreased GOR in patients receiving mechanical ventilation. A potential limitation in this study may have resulted from isotope administration, which was performed only once by a single instillation of the radiocolloid directly into the stomach. Although enteral nutrition was maintained, the scintigraphic study was performed $24 \mathrm{~h}$ following isotope administration [13]. The authors' feel that a continuous administration of radiocolloid makes it possible to detect sequential GOR and should be taken into consideration when the selected patients demonstrate a preserved gastric function and tolerate enteral nutrition. In the study by FERRER et al. [14], the patients were studied with two NGT: one tube with a $6 \mathrm{~mm}$ external bore and another with a $2.85 \mathrm{~mm}$ external bore. The authors demonstrated that small-bore NGT in intubated patients do not reduce GOR or microaspirations. In fact, no differences were found between the two NGT types on comparison of time course and cumulative RAc of pharyngeal and tracheal samples [14]. 


\section{Critique of the methods}

A crossover design was selected on the basis that it permits the control of most inter-individual variance. It avoids potential bias related to comparative analyses between different study groups (e.g. differences in gastric emptying, abdominal compliance, concomitant diseases, etc.). Specifically, the present study allowed for the comparison of the effect of the oesophageal balloon in the same individual during the same clinical condition and receiving both the same ventilation modality and pharmacological treatments. All patients remained clinically stable during the 2 days of study. Therefore, one can reasonably assume that most of the potential confounding factors were controlled. Consequently, the differences in GOR and bronchoaspiration of gastric contents should be attributed only to the inflated versus deflated balloon status.

This is the first study assessing the potential utility of a low-pressure oesophageal balloon in decreasing GOR and subsequent gastric content aspiration into the lower airways. For this reason, it was not possible to select a pressure according to recommendations or previous data. The current authors' aimed for a mechanical occlusion of the oesophageal lumen only. The pressure of the balloon was controlled and maintained at $30 \mathrm{cmH}_{2} \mathrm{O}$ during studies with the inflated balloon in order to minimise the possibility of ischaemia, necrosis, rupture or fistula of the oesophagus. These complications can be found in $\sim 15 \%$ of patients receiving oesophageal tamponade in oesophageal variceal bleeding. In case of balloon tamponade a higher balloon pressure than that indicated by the authors in the current study is applied to the bleeding varix in order to compensate the intravariceal pressure [22]. The arterial perfusion does not substantially diminish because the oesophagus, which lacks a serosal layer, is distensible. The current authors' reasonably assumed that a pressure of $30 \mathrm{cmH}_{2} \mathrm{O}$ (significantly lower than mean arterial pressure) would ensure perfusion through arteries and veins of the oesophagus in most of the mechanically ventilated patients. On the other hand, it has been shown that in the case of balloon tamponade, the longer the balloon is kept inflated the higher the possibility of local complications [23, 24]. This is important when evaluating whether a clinical application of the tube is required for several days, weeks or even months of mechanical ventilation. At present, there is a paucity of such prolonged studies.

\section{Potential clinical implications}

The present study clearly demonstrates that an inflated oesophageal balloon significantly delays and decreases the magnitude of both GOR and bronchial aspiration of gastric contents when compared to the effect of a semi-recumbent position only. These findings imply that the inflated oesophageal balloon actually imposed a protective obstructive effect on the GOR in patients receiving mechanical ventilation. Additional information is obtained, because besides evaluating a new device, the study also involved a longer study period for analysing GOR and bronchoaspiration dynamics in mechanically ventilated patients and emulated the continuous perfusion of enteral nutrition through the NGT. The study suggests that the device could be useful in combination with the semi-recumbent positioning of patients in preventing VAP. The role of the oesophageal balloon could be even more relevant in patients requiring mandatory supine position (e.g. shock), receiving paralysing or sedative agents, or showing decreased abdominal compliance or gastroparesia for various reasons during mechanical ventilation. Before recommending such a technique as a preventive measure for VAP, the longterm impact of the device on GOR and its safety have to be evaluated. Although the method was found to be safe when applied for $8 \mathrm{~h}$, longer times $(>24 \mathrm{~h})$ should be considered with caution. The present authors feel that the design of future protocols have to concentrate on two variables namely the minimum level of pressure that decreases or eliminates GOR, and the time period in which the balloon pressure is applied. Firstly, in addressing the minimum level of pressure, it may be possible to eventually apply pressures $<30 \mathrm{cmH}_{2} \mathrm{O}$ which would also yield favourable results. Secondly, the time duration of the applied balloon pressure, should initially be for $24 \mathrm{~h}$, and following successful reviews of safety may be extended for longer periods of time. These results could favour further evaluation of the effectiveness of the NGT with an oesophageal balloon in preventing nosocomial pneumonia in mechanically ventilated patients.

\section{Conclusion}

Using a nasogastric tube with an oesophageal balloon is a safe and effective method for reducing the magnitude of gastro-oesophageal reflux as well as protecting the airways from aspiration with contaminated gastric contents in patients receiving mechanical ventilation. These results favour further evaluation of the effectiveness of the nasogastric tube with an oesophageal balloon in preventing nosocomial pneumonia in mechanically ventilated patients. Further clinical trials assessing both the efficacy and safety of this preventive approach in patients requiring mechanical ventilation for several days, weeks or even months appears to be warranted.

\section{References}

1. Wenzel RP. Hospital-acquired pneumonia: overview of the current state of the art for prevention and control. Eur J Clin Microbiol Infect Dis 1989; 8: 56-60.

2. Gross PA, Neu HC, Aswapokee P, Van Antwerpen C, Aswpokee N. Deaths from nosocomial infections: experience in a university hospital and community hospital. $\mathrm{Am} \mathrm{J}$ Med 1980; 65: 219-223.

3. Andrews CP, Coalson JJ, Smith DJ, Johanson WG Jr. Diagnosis of nosocomial bacterial pneumonia in acute, diffuse lung injury. Chest 1981; 80: 254-258.

4. Jiménez P, Torres A, Rodriguez-Roisin R, de la Bellacasa JP, Aznar R, Gatell JM. Incidence and etiology of pneumonia acquired during mechanical ventilation. Crit Care Med 1989; 17: $882-885$.

5. Meduri GU. Ventilator-associated pneumonia in patients with respiratory failure. A diagnosis approach. Chest 1991; 100: 439-444.

6. Du Moulin GC, Paterson DG, Hedley-White J, Lisbon A. Aspiration of gastric bacteria in antiacid-treated patients: a frequent cause of postoperative colonization in the airway. Lancet 1982; 1: 242-245.

7. Johanson WG Jr, Pierce AK, Sandford JP, Thomas GD. Nosocomial respiratory infections with gram-negative bacilli: the significance of colonization of the respiratory tract. Ann Intern Med 1972; 77: 701-706.

8. Nagler R, Spiro HM. Persistent gastroesophageal reflux induced during prolonged gastric intubation. $N$ Engl $J$ Med 1963; 269: 495-500.

9. Torres A, Serra-Batlles J, Ros E, et al. Pulmonary aspiration of gastric contents in patients receiving mechanical ventilation: the effect of body position. Ann Intern Med 1992; 116 : 540-543.

10. Ibañez J, Peñafiel A, Raurich JM, Marse P, Jordá R, Mata F. Gastroesophageal reflux in intubated patients receiving enteral nutrition: effect of supine and semi-recumbent positions. J Parent and Enteral Nutrit 1992; 16: 419-422. 
11. Mahul P, Auboyer C, Jospe R, et al. Prevention of nosocomial pneumonia in intubated patients: respective role of mechanical subglotic secretions drainage and stress ulcer prophylaxis. Intensive Care Med 1992; 18: 20-25.

12. Vallés J, Artigas A, Rello J, et al. Continuous aspiration of subglottic secretions in preventing ventilator-associated pneumonia. Ann Intern Med 1995; 122: 179-186.

13. Ibáñez J, Peñafiel A, Marsé P, Jordá P, Raurich JM, Mata F. Incidence of gastroesophageal reflux and aspiration in mechanically ventilated patients using small-bore nasogastric tubes. JPEN 2000; 24: 103-106.

14. Ferrer M, Bauer TT, Torres A, Hernandez C, Piera C. Effect of nasogastric tube size on gastroesophageal reflux and microaspiration in intubated patients. Ann Intern Med 1999; 130: 991-994.

15. Drakulovic MB, Torres A, Bauer T, Nicolas JM, Nogué S, Ferrer M. Supine body position is a risk factor of nosocomial pneumonia in mechanically ventilated patients: A randomized clinical trial. Lancet 1999; 354: 1851-1858.

16. Orozco-Levi M, Torres A, Ferrer M, et al. Semi-recumbent position protects from pulmonary aspiration but not completely from gastroesophageal reflux in mechanically ventilated patients. Am J Respir Crit Care Med 1995; 152: 1387-1390.

17. Jacobs S, Chang RWS, Lee B, Bartlett W. Continuous enteral feeding: a major cause of pneumonia among ventilated intensive care unit patients. J Parent and Enteral Nutrit 1990; 14: 353-356.

18. Matthews JNS, Altman DG, Campbell MJ, Royston P Analysis of serial measurements in medical research. $B M J$ 1990; 300: 230-235.

19. Helm JF, Dodds WJ, Riedel DR, Teeter BC, Hogan WJ, Andorfer RC. Determinants of esophageal acid clearance in normal subjects. Gastroenterology 1983; 85: 607-612.

20. Schulze-Delrieu K. Esophageal pharmacology. In: Cohen S, Soloway SD, eds. Diseases of the Esophagus. New York, Churchill-Livingston, 1982; pp. 35-39.

21. Satiani B, Bonner JT, Stone H. Factors influencing intraoperative gastric regurgitation. A prospective random study of nasogastric tube drainage. Arch Surg 1978; 13: 712-723.

22. Avgerinos A, Armonis A. Balloon tamponade technique and efficacy in variceal haemorrhage. Scand $J$ Gastroenterol Suppl 1994; 207: 11-16.

23. Vlavianos P, Gimson AE, Westaby D, Williams R. Balloon tamponade in variceal bleeding: use and misuse. BMJ 1989; 298: $1158-1159$

24. Cook D, Laine L. Indications, technique, and complications of balloon tamponade for variceal gastrointestinal bleeding. J Intensive Care Med 1992; 7: 212-218. 